\title{
CONFIGURACIONES DE LO SAGRADO EN LA LITERATURA CONTEMPORÁNEA DEL CONO SUR
}

\author{
POR \\ Marta InÉs WaLdegaray \\ Université de Reims Champagne-Ardenne
}

Leer la presencia de lo sagrado en la literatura de las últimas décadas del Cono Sur es el propósito que dio impulso a este volumen. La propuesta parte de una constatación: en la era de la ciencia, en la era del funcionamiento tecnócrata y maquínico de nuestras sociedades, (un funcionamiento que recusa jerarquías y prioridades en nuestra forma de vida, que necesita de la evanescencia del sentido de las cosas, para confortar su ritmo acelerado), lo sagrado, entendido como misterio del sentido y recuperación de la trascendencia, goza de buena salud. No parece ser en nuestro presente una reliquia, un residuo de épocas pasadas, un arcaísmo del pensamiento. Es un acontecimiento perteneciente al orden del discurso, una ficción inclusive si se quiere, de intenso poder performativo. Un rictus que la literatura en su poderío interpretativo y simbólico no excluye.

Desde el punto de vista analítico, la reflexión acerca de lo sagrado permite por lo menos tres perspectivas, que se encuentran entrelazadas por cierto en la experiencia práctica. Brevemente, la primera perspectiva tiene que ver con la problemática institucional que examina cómo se agencian los dispositivos de selección, construcción, legitimación de espacios sagrados garantizados institucionalmente por leyes, discursos, prácticas, dogmas, una doxa que funciona sobre el modo de la evidencia común o de la revelación. La segunda perspectiva, responde a la dimensión cultual constituida por ritos públicos o privados que enmarcan el contacto con lo sagrado garantizando su respeto, difusión y consumo. La tercera vía, aborda la noción de sacralidad en su accionar, esto es, como fuerza performativa del pensamiento que estipula los perímetros de la palabra determinando lo que se debe decir y callar, lo que resulta o no políticamente correcto. Es en este último sentido que, por ejemplo, los acontecimientos trágicos que Francia vivió entre el siete y el nueve de enero de 2015 ponen en evidencia la importancia simbólica y real de lo sagrado en la vida cotidiana. Las nociones de sacrilegio, blasfemia, profanación son factores sígnicos sobre los cuales se sostiene el orden simbólico y el sentimiento de cohesión de una comunidad, pero que también funcionan como energía performativa que se traduce en obra de vida y de muerte (Miller). 
El eje de los estudios de este volumen se orienta hacia la tercera de estas perspectivas, puesto que elige interrogar las modalidades de apropiación de los códigos de lo sagrado por el discurso literario y los usos que este discurso realiza de los códigos que constituyen lo sagrado. Los investigadores que participan en este volumen estudian la manera en que lo sagrado se literaturiza permitiendo que la palabra, la sintaxis, un personaje-tipo, un imaginario ficcional resuenen de otra manera hasta poder inclusive politizar lo sagrado, en el sentido de "hacer política en tanto literatura", según la expresión de Jacques Rancière (2007). Es decir, interpretar cómo la literatura en tanto organización formal del discurso, que establece una relación polisémica con el saber y en consecuencia con la verdad, incorpora un tipo de discurso que se sostiene sobre un principio de verdad identificable como trascendental, en sus múltiples facetas de lo divino, lo numinoso, lo sublime, lo originario.

Exponiendo una multiplicidad de dispositivos teóricos, las contribuciones de este volumen leen la temática propuesta en la literatura del Cono Sur de los últimos cincuenta años. Aportan nuevas perspectivas y sólidas reflexiones sobre la manera en la que la conceptualización de lo sagrado abre una brecha en la escritura sureña, en tanto espacio literario (Blanchot) conformado por escrituras que hablan de ausencias, de soledad, de sinsentido, de incertidumbre como condición del lenguaje poético, pero también, como densidad histórica de ese espacio escritural. Más que delimitar de manera esencialista la adecuación entre un conjunto de propiedades teóricas y la descripción del objeto estudiado (lo sagrado), los artículos de este volumen restituyen las apuestas textuales de los escritores tratados en función de objetivos literarios y de estrategias de empleo de la noción en cuestión. Ni sentido inmanente (estructuralismo), ni ciencia de la letra (filología), ni sentido secreto (hermenéutica), estas contribuciones invitan a leer los empleos literarios de lo sagrado en su polivalencia semántica, y esto, sin desestimar su consistencia histórica, su racionalidad política, encarnadas en la materialidad discursiva e imaginaria (afectiva, intelectual y ética) de las obras y de los escritores analizados. Distinguir los modos, lugares y tonos en los que lo sagrado es agenciado por la literatura lleva a los contribuyentes de este volumen a abordar la noción de sacralidad de manera empírica, como sintaxis, experimentación y cadencia (Deleuze). ${ }^{1}$

Dimensión de lo real que nos sobrecoge y fascina a la vez; emergencia de lo lumínico trascendente en la prosa de lo diario (Otto); potencia numinosa de lo arcaico; ruptura con el curso cotidiano de la vida y por lo mismo encuentro con las raíces que religan (Eliade); energía útil pero peligrosa por ser difícil de manejar (Berger, Callois); reunión de lo bendito y lo maldito; profunda necesidad de certidumbre; experiencia espiritual

1 Al respecto, Gilles Deleuze señala en Dialogues: “C'est cela l'empirisme, syntaxe et expérimentation, syntaxique et pragmatique, affaire de vitesse" (73).

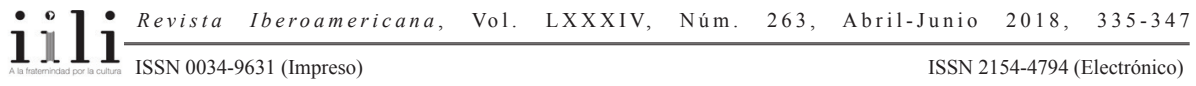


o aprendizaje de sí en el sentido foucaultiano de un souci de soi; ${ }^{2}$ empleo siempre distanciado y venerado del objeto observado, pero también experiencia aurática que puede conducir hacia una cierta forma de resistencia de los sentidos o del pensamiento al remitir, como lo sostenía Walter Benjamin, hacia "la manifestación irrepetible de una lejanía (por cercana que pueda estar)" (24), lo sagrado puede comportar una negatividad capaz de frenar la precipitación del tiempo. Este es el panorama de sentidos y enfoques de lo sagrado que los autores de este volumen estudian en textos de una veintena de escritores sureños.

El volumen consta de quince artículos de investigadores y docentes reconocidos por sus reflexiones sobre el tema o acerca de los autores tratados; pertenecen a universidades y centros de investigaciones europeos (Bélgica, Francia, Holanda) y americanos (Argentina, Chile, Estados Unidos). La literatura contemporánea del último medio siglo de Argentina, Chile, Uruguay y también Brasil está representada en los análisis de la narrativa o de los textos poéticos de los argentinos Juan L. Ortiz, Juan Manuel Inchauspe, Juan José Saer, Néstor Perlongher, Leónidas y Osvaldo Lamborghini, Daniel Guebel, Edgardo Dobry, Hugo Mujica, Héctor Viel Temperley, Hugo Padeletti y Oscar del Barco; de los chilenos Roberto Bolaño, Nicanor Parra, Raúl Zurita y Cynthia Rimsky; de los uruguayos Mario Levrero y Marosa di Giorgio; como también de la brasileña Clarice Lispector.

Tres ejes transversales articulan los artículos y los agrupan en tres secciones. Se trata de: refugios, orígenes y lo maldito. Los trabajos reunidos en la primera sección son cinco y dan cuenta de las configuraciones de lo sagrado que nidan en cinco instancias de amparo: la inspiración, la espiritualidad ritual, la voz profética, la caminata y los detalles cotidianos. La segunda sección abarca seis artículos que abordan diferentes maneras en que lo sagrado se manifiesta en relación con alguna manera de revelar el origen: el existencial, el de la palabra. Estos trabajos se interesan por el estallido poético de la palabra, la ritualización de la memoria, lo sublime que se nos muestra, la falta que se nos revela, y, también, por sus desacralizaciones. Finalmente, la tercera sección consta de cuatro artículos que analizan lo sagrado como experiencia del sentido en la cual el mal se revela como envés horroroso de lo cotidiano, intimidad maldita del ser, intensidad misteriosa de la vida.

La primera sección, REFUGIOS, se inicia con un ensayo acerca de la inspiración en el proceso creador. En "Las agujas del cielo", Sergio Delgado interroga en el proceso creativo la presencia de lo sagrado como intuición irracional, revelación, inspiración. Propone, por un lado, una lectura del carácter pasivo que ha adquirido la inspiración

2 Escribe Michel Foucault en Histoire de la sexualité: "La place qui est faite à la connaissance de soimême devient plus importante: la tâche de s'éprouver, de s'examiner, de se contrôler dans une série d'exercices bien définis place la question de la vérité - de la vérité de ce que l'on est et de ce qu'on est capable de faire- au cœur de la constitution du sujet moral" (90).

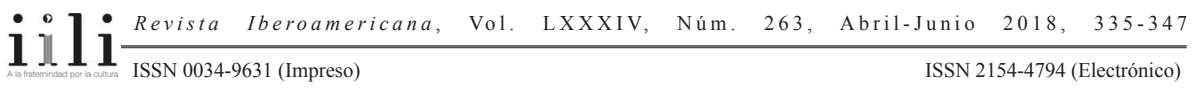


en la concepción occidental, y por otro lado, ofrece una lectura de la profanación de esta noción, esto es, de su condición progresivamente profana. Inscripta en el trabajo intelectual y por extensión en el acto creativo como enigma del origen de la escritura y también de la lectura, suerte de fantasma del pensar constantemente disimulado, si no claramente negado en el mundo académico, la inspiración está, según sostiene Delgado, siempre vigente en el sendero que va de los enigmas del proceso creativo al resultado final. El crítico argentino analiza agudamente en el arte poético las declinaciones de lo sagrado a través de las figuraciones que la inspiración adopta como experiencia mental o estado espiritual en la poesía argentina contemporánea posterior a Juan L. Ortiz, particularmente en poetas próximos a su sistema que retomaron el hilo de los interrogantes poéticos del escritor entrerriano. Se trata de poetas como Hugo Padeletti, Juan José Saer y Juan Manuel Inchauspe. Recurriendo a un vasto panorama teórico que incluye filósofos como Platón, Friedrich Nietzsche, Gilles Deleuze, Giorgio Agamben, y también poetas como Paul Claudel y Louis Aragon, Delgado sostiene que el pensamiento barroco significa un momento crucial de resistencia creadora contra la separación entre lo sagrado y lo profano; aunque sorprendentemente el Barroco sea también-según lo precisa Delgado- un período en el cual el trabajo del artista renuncia a la idea de la inspiración divina. Si bien el carácter espiritual, aéreo, lumínico persiste en el concepto de inspiración, es en el siglo XVII cuando la secularización de la noción de inspiración se afianza. En el orden del pensamiento creador, lo sagrado -nos dice Delgado- encuentra refugio en el impulso liberador de lo no racional.

El siguiente artículo está destinado a la obra del escritor argentino Néstor Perlongher. El investigador chileno Jorge Cid estudia en "El culto al Santo Daime en la escritura de Néstor Perlongher: entre la integración del imaginario daimístico como sustrato textual y la creación de himnos de finalidad ritual" un aspecto particular de la producción del escritor argentino: su práctica de la espiritualidad amazónica del Santo Daime, a la que, según explica Cid, Perlongher se adhiere como un sugestionado devoto. Sobre la base de ciertas entrevistas, correspondencia y textos literarios como el libro de poemas Aguas aéreas (1991) y el "Autosacramental del Santo Daime" (texto inconcluso publicado en 2001), dos obras de Perlongher estrechamente vinculadas con la experiencia del consumo en el contexto ritual de una bebida sagrada, la ayahuasca, Cid analiza la manera en que esta experiencia se inscribe textualmente en la obra de Perlongher. El artículo presenta en primer lugar algunos rasgos del lenguaje poético de Perlongher para luego demostrar de qué manera en su escritura aparecen integrados elementos relativos al trance místico. Otro elemento se suma al análisis que Cid propone: la atracción de este poeta argentino por el empleo del portugués caboclo, soporte lingüístico no estandarizado de las ceremonias de trance. El rito del Santo Daime resulta ser así para Perlongher una "inversión total de las coordenadas de dominación", en términos de Jorge Cid. Un dispositivo que controvierte la subalternidad, como previamente en el marco retórico-poético, lo había sido el neobarroco para Perlongher. Espiritualidad

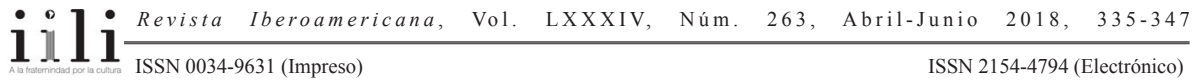


amazónica y práctica lingüística excéntrica se reúnen en el Daime para imbricar tres tipos de experiencias en las cuales lo sagado como práctica subjetiva de la espiritualidad se cuela: la experiencia corporal en estado fronterizo de trance sensual y místico; la experiencia del lenguaje devocional (con elementos propios a la cosmogonía daimística como la luz, el cosmos, las estrellas o el agua, entre otros); y la experiencia formal hímnica (verso corto con tendencia octosilábica, rimas consonantes y asonantes).

El tercer artículo de esta primera sección está dedicado a la poesía chilena. En “Los tiempos del p(r)o(f)eta en Nicanor Parra y Raúl Zurita", la crítica belga Geneviève Fabry estudia las modalidades que la voz profética adquiere en la poesía chilena contemporánea renovándose así la herencia del Pablo Neruda de Canto general (1950). Sobre el presupuesto de que la poesía moderna iniciada en el romanticismo alemán se forja sobre la constatación de que el lugar ocupado por Dios está vacío, y que desde este lugar vacante propio a una sociedad secularizada surge un lamento declinado según dos tonalidades en la poesía moderna: la angustia y la ironía. Fabry analiza dos poemarios publicados en 1979: Purgatorio de Raúl Zurita, por entonces joven poeta poco conocido, y (Nuevos) Sermones y prédicas del Cristo de Elqui del consagrado "antipoeta" Nicanor Parra, autores ambos distintamente ubicados en el campo literario chileno de finales de los setenta, pero en cuyos poemas se destaca el tono irónico y amargo con el que ambos ponen en evidencia las contradicciones de los lenguajes del poder. La originalidad del trabajo de Fabry radica en la manera en que lee lo sagrado desde la perspectiva de la ironía, y esto, al establecer que lo sagrado en estos poemarios radica en "el despliegue de una temporalidad que mucho tiene que ver con raíces religiosas que el hablante lírico afirma y niega al mismo tiempo". Esta temporalidad que Fabry postula siguiendo los pasos teóricos de Agamben se emparenta con la voz profética (que apunta al futuro, apocalíptico) y con la voz mesiánica (que se instala en la construcción del avenir desde el tiempo presente). Mientras que en los poemarios de juventud (Purgatorio 1979, Anteparaíso 1982), el sujeto lírico lúcido y autocrítico de Zurita adoptaba la temporalidad profética, los poemarios de su madurez (como INRI, 2003) dan mayor cabida a la experiencia histórica (el golpe de Estado de 1973, la represión) y se orientan más hacia un mesianismo escatológico. Con los matices propios de cada autor que Fabry analiza sutilmente, el dispositivo enunciativo de estos poemarios de Parra y de Zurita desorienta la isotopía religiosa mediante la inclusión de voces coloquiales, vulgares y/o escabrosas, y de referencias religiosas disparatadas no carentes de crítica política. En definitiva, la ironía sería en ellos, según la hipótesis de Fabry, un dispositivo retórico e ideológico que vehicula juegos de antífrasis (en Zurita) e involuntarios efectos dramáticos (en Parra) que "crucifican" la escritura, puesto que en ella lo que se afirma y lo que se niega coexisten.

El cuarto estudio está destinado a la obra de la escritora chilena Cynthia Rimsky. La investigadora María Paz Oliver indaga el acto de caminar como intercambio reflexivo con el paisaje que lleva a un encuentro con lo sagrado. En "Paseos sagrados:

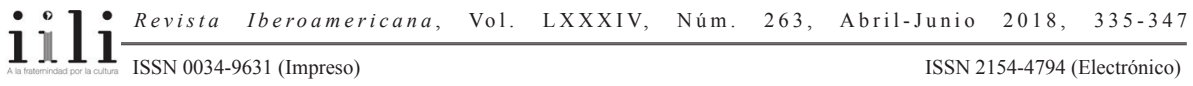


caminata y peregrinaje en Poste restante de Cynthia Rimsky", Oliver analiza la dimensión espiritual de la peregrina caminata que la protagonista de esta novela de Rimsky -publicada en 2001-emprende por las tierras de sus antepasados en la Europa del Este, en busca de la historia familiar; un desplazamiento meditativo que reescribe la mítica figura del "judío errante" retirando lo sagrado de la dimensión religiosa e inscribiéndolo en el movimiento de la caminata, en la cotidianidad del paseo urbano. Así, flâneuse y peregrina, la protagonista de Rimsky hace de sus desplazamientos por la tierra de sus antepasados un modo de reflexionar sobre sus orígenes extranjeros y su identidad familiar judía. El trabajo de la investigadora chilena aporta una interesante lectura bibliográfica sobre el acto de caminar como búsqueda terapéutica o evasiva de una experiencia espiritual, como estímulo del pensamiento reflexivo. La dimensión espiritual de la caminata promueve un ritmo lento y meditativo que invita a reflexionar sobre la cotidianidad del presente y/o el mundo interior. "La caminata [escribe Oliver citando a David Le Breton] es ese momento en que la presencia en el mundo se vuelve a convertir en una forma de espiritualidad".

La quinta y última contribución que integra la primera sección se centra en la producción del escritor uruguayo Mario Levrero. En "El proyecto de un sujeto entre lo sagrado y lo profano en La novela luminosa de Mario Levrero", la crítica mexicana Christina Soto van der Plas analiza cómo la descripción obsesiva de lo cotidiano deriva en un encuentro con lo lumínico-sagrado en la célebre novela del escritor uruguayo. El deber de escribir experiencias trascendentes que el narrador de Levrero se autoimpone lo lleva a la descripción obsesiva de lo cotidiano. Paso a paso, lentamente, en una suerte de camino ascendente (a la manera de la escritura de los místicos) que conduce a la revelación final, la escritura de Levrero se va forjando desde la esfera profana del diario acontecer; en su registro, ningún detalle resulta intrascendente ni es excluido de la mirada recolectora del narrador. La convicción de que la materia es "perversa" y de que hay en ella un más allá de lo visible, de que un "ser invisible" existe, motiva la búsqueda constante de instantes privilegiados (sagrados) con el propósito de percibir esa esfera luminosa, de difícil acceso y de aún más laboriosa comunicabilidad en términos literarios. La novela luminosa (2005) da cuenta de ese proyecto de retener en la escritura esos instantes privilegiados con el objetivo de hacerlos reaparecer en el proyecto de una novela. Narrar la experiencia de estas revelaciones condiciona la organización de la escritura a la vez que erige una subjetividad autotélica que confía a la escritura literaria la misión de una indagación espiritual que se da en directa relación con la busqueda constante de la excepcionalidad sagrada.

En el primer trabajo de la segunda sección del volumen, ORÍGENES, la docente y crítica francesa Pénélope Laurent estudia la temática de la desaparición de los dioses en la obra narrativa de Juan José Saer. Se centra en el estudio del espacio que Saer denominó la "Zona": espacio de representación de su propio lugar de origen, pero también, espacio de figuración temática de su proyecto estético y de su praxis poética.

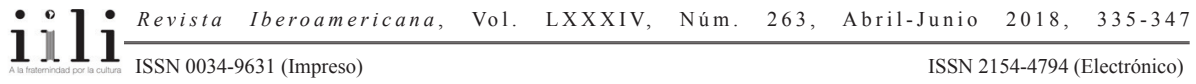


Laurent sostiene en su artículo "Melancolía de lo sagrado en la obra de Juan José Saer" que la temática de lo sagrado es una constante en la obra saeriana y que siempre aparece desvinculada de lo divino. "De la zona-escribe Laurent-han desaparecido los dioses", pero lo sagrado persiste diseminado en las revelaciones epifánico-numinosas de sus personajes, en los ritos colectivos que los ligan, o en el tono sarcástico de la instancia narrativa. Sobre la base de un aparato crítico interdisciplinario que va del psicoanálisis a la antropología, pasando por la historia de las religiones, la filosofía y la lectura de pensadores ya clásicos sobre el tema como Sigmund Freud, Rodolf Otto, Mircea Eliade, Roger Caillois, Georges Bastide, y también de otros prolíficos intelectuales contemporáneos como Giorgio Agamben, Marcel Gauchet y Pierre Bayard, Laurent analiza la desacralización del mundo en la obra saeriana interesándose tanto por los procedimientos de fragmentación organizativa, el uso paródico o desviado de textos canónicamente reconocidos como sagrados, así como por la temporalidad pasada, mítica, evocada en la obra del escritor argentino.

En el segundo artículo de la sección, Valentina Litvan repasa los orígenes orales del lenguaje poético, que hoy en día, según sostiene, tenemos tendencia a olvidar. Desde esta hipótesis, la crítica española analiza en "Profanar el lenguaje. Contratiempo de Edgardo Dobry" el último poemario del poeta argentino, publicado en 2013. Litvan destaca la manera en que en sus poemas Dobry otorga un espacio a la lengua hablada, un habla que irrumpe en un registro escrito de carácter neobarroco, extremadamente elaborado. Los cruces de la oralidad con la escritura son el correlato de otras tensiones presentes en sus poemas, como las tensiones entre espontaneidad y artificio, realidad cotidiana y abstracción conceptual, lenguaje comunicativo y lenguaje confirmado. Estas tensiones dan cuenta de una pérdida de sentido consagrado por la tradición poética, que aflora en los poemas de Dobry como desliz humorístico en la agudeza graciosa del Witz. Litvan estudia la manera en la que Dobry explora tanto los alcances semánticos de nuestra lengua castellana, como también el sentido político que puede tener hoy la poesía. Entre escritura autotélica de tradición simbolista y convicción vanguardista que postula que todo puede ser material poético, Contratiempo asigna al poema de nuestro tiempo un nuevo lugar. Así, el interrogante acerca de la relación posible entre la poesía y lo sagrado se reconfigura, en el caso concreto de este poemario, indagando los vestigios de lo sagrado en una lengua poética permeable a las modulaciones propias del castellano de uso cotidiano. La transmisión resulta ser así un tema central en este libro. "Leer la tradición desde esta perspectiva -precisa Litvan-, como una resignificación y ya no como la búsqueda de un sentido original que debiera preservarse, recuerda la técnica exegética bíblica de la midrash, basada, por lo demás, en la tradición de comentarios orales". Esta articulación entre la oralidad del judaísmo y la escritura es en Dobry una manera de desacralizar las referencias ya cristalizadas (sean éstas bíblicas, mitológicas o literarias) y de cuestionar en consecuencia la transmisibilidad de un sentido originario, consagrado. Al entrar en consonancia con las voces de la vida

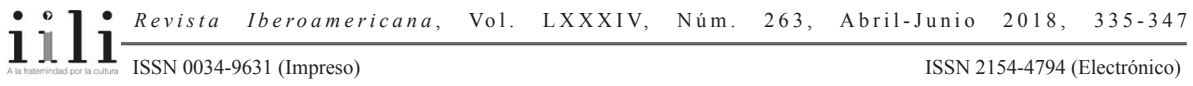


cotidiana de nuestra modernidad, estas referencias culturales interactúan de manera desjerarquizada brindando una imagen intrascendente de lo culturalmente confirmado.

En el siguiente trabajo, "El Concilio: notas sobre las "sagradas letras" en Trento de Leónidas Lamborghini (y otras novelas argentinas)", Martín Arias analiza cómo la literatura argentina de finales del siglo XX y principios del presente siglo imagina tres figuras de la historia de la religión: la del hereje, la del teólogo y la del traductor como formas-de-vida (siguiendo a Agamben), como intensas experiencias ligadas a la escritura de lo sagrado que entran en contacto con las "sagradas letras". Las experiencias del hereje y del teólogo son principalmente analizadas en el mundo ficcional de Trento (2003) de Leónidas Lamborghini; la del traductor y la de su encuentro trágico con la palabra sagrada son estudiadas en otros dos textos que Arias relaciona con esta novela, se trata de: Tadeys (1983) de Osvaldo Lamborghini y Cuerpo cristiano (1994) de Daniel Guebel. En el corpus analizado por Arias, lo sagrado está esencialmente relacionado con diversas fuentes teológicas del cristianismo, con textos que son reactivados en la reescritura narrativa y poética de los hermanos Lamborghini y de Guebel. Se trata de las Epístolas de Pablo, los Ejercicios espirituales de San Ignacio de Loyola, pero también de referencias a textos y géneros literarios consagrados de la literatura argentina, como por ejemplo el "Evangelio según Marcos" de Borges (que recoge a su vez referencias bíblicas) y el género gauchesco (en el cual la palabra de doble sentido que induce al equívoco se destaca y necesita a menudo de una traducción). La palabra sagrada retrabajada es en estos textos seleccionados por Arias palabra delirante, enloquecida, estallada y también, por lo mismo, abierta a una multiplicidad de versiones. Lo sagrado se revela aquí a través de frases dislocadas, desfiguradas; se manifiesta en alaridos y restos de insultos. Lo sagrado es desopilante discurso hereje y barroco despliegue narrativo.

Andrea Cobas Carral estudia en el cuarto artículo de la sección, "Desacralizar el pasado reciente: la narrativa argentina de hijos de 'víctimas' de la violencia de Estado. Las escrituras de Mariana Eva Pérez y Angela Urindo Raboy”, el giro narrativo e ideológico que, en la literatura argentina de los últimos veinticinco años, adquiere el recuerdo de los militantes desaparecidos por la represión estatal en la narrativa de sus hijos. Si en la década de los setenta, la literatura argentina representó la lucha revolucionaria recurriendo a procedimientos como la metáfora y la alegoría; y en los años ochenta, dio cuenta del terrorismo de Estado privilegiando el relato testimonial de sus víctimas; en los noventa, la literatura se hizo eco de la irrupción en la escena pública de los hijos de víctimas de la violencia de Estado. Para contar la historia de los padres desaparecidos las novelas de la segunda generación se instalan en el espacio intersticial entre lo testimonial y lo ficcional, entre lo público y lo privado; proponen así otro ángulo para relatar lo vivido por la generación anterior. Las propuestas artísticas (literarias, fílmicas y plásticas) de hijos tienden a desacralizar la representación consagrada de los militantes desaparecidos como víctimas sacrificadas. En opinión de Cobas Corral,

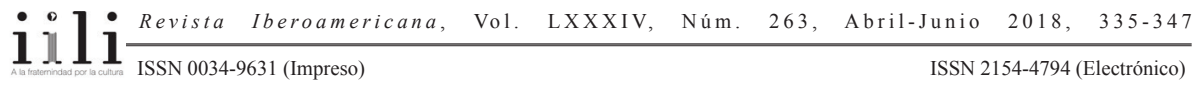


este carácter profanador del pasado que la crítica dio en llamar "posmemoria" (Hirsch) erosiona representaciones, explora con descreimiento, humor a veces, o autoironía, el uso cristalizado de ciertos sintagmas. Hijos modifica el ángulo desde el cual contar la orfandad y los recuerdos ya que, según sostiene Cobas Carral, desde los años de la dictadura, la matriz política que fundamentó la causa militante se vio desplazada por una lógica sacrificial de la heroicidad que hizo del desaparecido un mártir que ofrendó su vida por el bien común, sustrayendo así a los militantes desaparecidos de su terreno político (Agamben) y colocándolos en el lugar de la víctima inocente aniquilada por el terrorismo estatal. Sin aspirar a proclamar una verdad respaldada por la condición filial del autor, ni proponer "panfletos militantes que se legitiman en una experiencia subjetiva imposible de cuestionar" -nos dice Cobas Carral-, la narrativa de hijos profana la ritualización de la memoria. El artículo de esta investigadora argentina indaga en la escritura de Pérez y Urindo Raboy los matices ideológicos y las variantes narrativas de este trabajo de posmemoria.

En "Memorias sagradas, memorias profanas: Agamben y el discurso de lo sublime en la literatura posdictatorial argentina", quinto artículo de la sección, Silvana Mandolessi repasa el nutrido discurso crítico (Jean-François Lyotard, Shosana Felman, Claude Lanzmann) que sitúa los eventos de violencia extrema más allá del conocimiento y de la posibilidad de representación. En tal sentido, rescata el interés de la crítica contemporánea por la noción de lo sublime (Jacques Derrida, Lyotard, Slajov Žižek), que estaría así estrechamente ligado a lo sagrado en tanto contribuye a poner en evidencia un límite tremendo y fascinante surgido de una experiencia enigmática que se resiste a ser comprendida, y por ende, a ser puesta en palabras: "las palabras fallan", precisa Mandolessi. Sagrado y sublime invitan a reflexionar acerca de los límites de lo pensable, lo cognoscible, lo representable. Sin embargo, Mandolessi observa con agudeza crítica que la literatura argentina de los últimos veinte años no privilegia lo sublime para representar la represión de Estado. Estableciendo una analogía entre el homo sacer y el desaparecido político, sostiene que: "la aproximación a la experiencia de la desaparición -y con experiencia nos referimos a los modos de inscripción de una experiencia histórica en la trama de sentido de la comunidad- es esencialmente "profana". Estima que las llamadas novelas de la segunda generación, escritas por hijos de desaparecidos (Pérez, Félix Bruzzone, Patricio Pron, Julián López), son particularmente apropiadas para explorar lo expuesto y, con el fin de analizar las "estrategias profanas" de representación de la desaparición en la literatura argentina reciente, Mandolessi centra su análisis en la novela de Ernesto Semán: Soy un bravo piloto de la nueva China. Soy un bravo piloto... (2011). La investigadora argentina explicita, desarrolla y adopta a lo largo de su análisis la perspectiva desarrollada por Agamben en Homo sacer, vindica para la política una esfera propia no adosada a lo religioso (René Girard), refuta la tradición filosófica que entiende lo sagrado como una ambigüedad y ambivalencia constitutiva, y propone una lógica de la excepción para

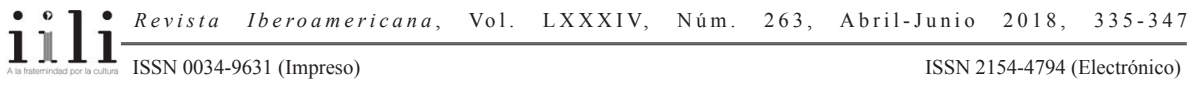


explicar la reconfiguración de lo sagrado y su relación con el desaparecido político en las novelas recientes sobre el pasado dictatorial escritas por la segunda generación, puesto que ni totalmente vivo ni definitivamente muerto, el desaparecido se caracteriza por estar sometido a un espacio espectral de indiferenciación.

La sexta y última contribución de la segunda sección, indaga el lenguaje poético en su relación con la sacralidad desde una perspectiva acentuadamente filosófica. En "Ausencia de Dios. Lo sagrado en el pensamiento y la poesía", Gabriela Milone reexamina categorías centrales del análisis sobre lo sagrado desde una multiplicidad de perspectivas teóricas como son las reflexiones que sobre el tema aportaron Georges Bataille, Maurice Blanchot, Martin Heidegger, Michel Foucault, Emmanuel Levinas, Jean-Luc Nancy y Jean-Luc Marion, entre otros. La investigadora argentina interroga el vaciamiento de lo sagrado como problemática del lenguaje poético ajena al debate teológico-político sobre lo que se dio en llamar retorno de lo religioso. Lo sagrado sucede en la falta que queda ante el vaciamiento de la idea de Dios; es "experiencia del afuera de las significaciones", es "energía que disloca la realidad discursiva", sostiene Milone. La sólida reflexión teórica y textual que Milone realiza en este trabajo apunta centralmente a estudiar los recursos y rodeos mediante los cuales la poesía libera la palabra de sus significados tradicionales; se propone indagar cómo la singularidad de la experiencia poético-religiosa manifestada en la ausencia, el vaciamiento o la falta de lo sagrado acontece en las obras de cuatro poetas argentinos: Hugo Mujica, Héctor Viel Temperley, Hugo Padeletti y Oscar del Barco. Sostiene que en Mujica, la experiencia de lo sagrado es vaciamiento de Dios y paraíso perdido. En Temperley y en Padeletti, la experiencia de lo sagrado se emparenta con la mística, aunque en este último, como el poeta mismo lo precisa, se trate de una mística de "la atención", exenta de connotaciones religiosas, que recepciona simplemente lo que se nos puede revelar una vez despojada la mente de conceptos racionalistas, como si fuera un "milagro de la simplicidad original". En los poemas de Barco, Milone encuentra que la gracia del acontecimiento poético surge de la intimidad que se libera en la ruptura producida entre el yo lírico y el lenguaje.

La tercera y última sección, LO MALDITO, está inaugurada por el artículo de Paula Aguilar, "Ningún lugar sagrado: derrota, violencia y escritura en Roberto Bolaño". El ensayo se inscribe en la línea de los estudios que exploran la cultura revolucionaria setentista en América Latina, y particularmente en el Cono Sur, para reexaminar la representación del sacrificio militante elevado al rango de creencia. Como Cobas Carral en su artículo sobre la narrativa de hijos, y en la línea también del estudio de Silvana Mandolessi, Aguilar interroga en la literatura del Cono Sur las representaciones más recientes del militante setentista que escapan a las figuras de la víctima, el traidor, el héroe, el mártir y sostiene que, desde los años noventa, la literatura argentina propone un nuevo escenario de enunciación para dar cuenta de la experiencia de la lucha armada y de la derrota. Aguilar indaga el tópico de la generación revolucionaria sacrificada y

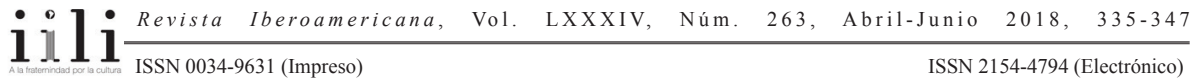


la melancolía como tono narrativo de la derrota en Estrella distante (1996) y Amuleto (1999) de Roberto Bolaño. Analiza en estos textos cómo el escritor chileno se distancia de la juventud sacrificada como motivo ideológico-discursivo, y, también, de la creencia militante en la muerte purificadora. Explorando al célebre protagonista de Estrella distante, Carlos Wieder, Aguilar estudia los alcances políticos del mal como programa artístico. Artista del terror, poeta-sacerdote que asume un proyecto macabro, Wieder representa lo contrario de la "banalidad del mal" evocada por Hannah Arendt. En los noventa entonces, Bolaño rescata el ethos revolucionario, pero lo hace-según Aguilar-desde un envés horroroso. La compleja figura de Wieder, desplaza la creencia en la trascendencia benefactora del arte hacia una puesta en práctica de la crueldad programada y asumida como vanguardia del mal.

El siguiente artículo, "Entre lo sagrado y lo profano: literatura, barbarie y silencio inmaculado en Nocturno de Chile de Roberto Bolaño", del investigador argentino Enrique Schmuckler, es el segundo trabajo sobre la obra del escritor chileno que presenta este volumen. El análisis se centra en esta oportunidad en el protagonista de Nocturno, el sacerdote Sebastián Urrutia Lacroix, personaje que ama la literatura y comulga arte con represión. Schmuckler analiza agudamente cómo la tensión entre lo sagrado y lo profano orienta la conciencia de este personaje que recuerda, hacia el final de su vida, la invitación que el crítico literario Farewell le hiciera para visitar su fundo. Schumuckler se vuelca hacia la lectura de tres aspectos temáticos de la novela: la noción de espacio sacralizado; la importancia del vestido y la desnudez en Lacroix y el sentido cristiano de la Historia. Eliade, Agamben y Bayard son los intelectuales que modelan la lectura que el investigador argentino hace de la experiencia vivida por Urrutia Lacroix en su juventud, cuando ya sacerdote realizó su pasaje hacia la finca de Farewell, espacio desconocido y reacio, lugar de experiencias estremecedoras, terra incognita de la Literatura, là-bas en el cual el sacerdote recibe las primeras embestidas demoníacas de lo literario que significarán su iniciación poética. De la teoría de la infancia de Agamben, centrada en la interpretación de la experiencia de la palabra y de su poderío, Schumuckler extrae la oposicion antropológica entre naturaleza y cultura (del mal, de la barbarie). De los argumentos agambianos sobre la desnudez, concebida como falta y no como pureza, Schmuckler lee la tensión sentida por el sacerdote entre el cuerpo y su envoltura (sotana, ropa de seglar) y evoca la desnudez sin vergüenza de la tradición cristiana. El tercer elemento de análisis radica, por un lado, en la noción de historia irreversible de filiación cristiana (Bayard), presente en Nocturno de Chile (2000); y por otro lado, en el carácter digresivo del tiempo entendido como fuga constante hacia adelante cuya culminación es el Juicio final, el Apocalipsis.

En el tercer artículo de esta sección Natalia Lorio estudia el universo de la escritora brasileña Clarice Lispector. En "La experiencia de lo sagrado en La pasión según G.H. Elementos de un ateísmo materialista en Lispector", Lorio aborda lo sagrado como experiencia de ruptura existencial y hace hincapié en la ambivalencia del fenómeno

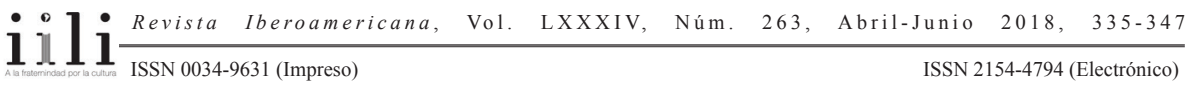


revelado. Basándose en el pensamiento teórico desarrollado por Bataille, Phillipe Borgeaud, Caillois, Emil Durkheim, Michel Leiris, Nancy y Otto, la investigadora argentina analiza lo sagrado como una irrupción íntima de raros estados cercanos a la muerte y lejanos a la imagen de Dios. En La pasión según G.H. (1964) de Clarice Lispector, lo nefasto, lo maldito y lo impuro sobredeterminan lo sagrado, que la escritora brasileña narra como una experiencia de retorno a la intimidad maldita del ser y a la intensidad misteriosa de la vida. Lejos de ser apaciguadora o de conducir a una experiencia mística o piadosa, la experiencia de lo sagrado que relata Lispector indaga -según Lorio- las profundidades de la vida, hondura existencial que vuelve confuso el acontecer cotidiano así como las certezas emanadas de aquello que nos es conocido. Puesto lo sagrado en contacto con lo más primario y rudimentario de la vida (el líquido blanco que se encuentra en el interior de una cucaracha en La pasión...), la novela de Lispector reconfigura lo sagrado como una relación disruptiva con lo divino, como experiencia de lo bajo. Esta reunión de lo sagrado con lo maldito en la intimidad de la subjetividad desgarrada de G.H. (la narradora) conduce también a Lorio a interrogar la condición demoníaca de la literatura siguiendo la línea de pensamiento sostenida por Bataille.

La contribución de Adriana Gabriela Canseco completa esta tercera sección y cierra el volumen. Inscribiéndose en la línea de análisis de Bataille, la crítica argentina propone una lectura de la poesía de la escritora uruguaya Marosa di Giorgio recopilada en Los papeles salvajes (1970-2000) desde el punto de vista de lo sagrado como experiencia lingüística de lo extremo. En "Escritura y transgresión en los umbrales del cuerpo y del lenguaje. La apertura hacia una experiencia de lo sagrado en la poesía de Marosa di Giorgio", Canseco reflexiona acerca de la experiencia de lo sagrado en la poética marosiana como correlato gozoso de su escritura abigarrada. En constante tensión entre prohibición y transgresión, el inventario animista de criaturas, objetos y fluidos varios presente en los poemas de la escritora uruguaya es la religiosidad que en sus textos da paso a lo sagrado. Santas, vírgenes, ángeles, hadas, animales fantásticos, espíritus, sombras y la presencia tutelar de los antepasados conviven en su poesía con la celebración carnavalesca del goce femenino, con el cuerpo deseante que instaura su propia liturgia. Esta coexistencia de la experiencia erótica con la experiencia de lo sagrado lleva a la especialista de la poesía marosiana que es Adriana Canseco a emparentar este cruce con los postulados de Bataille acerca del lugar del Mal en la literatura como instancia que da cauce al exceso a través de la exploración de los límites de la significación. La hipótesis de Canseco es que lo sagrado da cauce a la "parte maldita" de la poesía de Giorgio; lo sagrado es rastreo de lo divino a través de la trangresión erótica, de la voluptuosidad finalmente encontrada en el propio cuerpo transido de gozo; lo sagrado marosiano -sostiene Canseco-es "riesgo, azar, sacrificio, dispendio, excedencia".

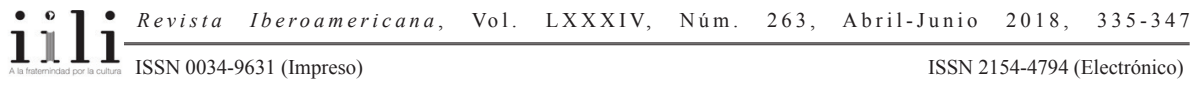


La propuesta de estudio que reúne a los artículos de este libro en torno a las configuraciones de lo sagrado en la literatura de los últimos cincuenta años en el Cono Sur es vasta y el bagaje teórico (filosófico, antropológico, estético y político) que la cubre es una empresa mayúscula que este volumen no puede ni ambiciona agotar. Diversos son los enfoques teóricos que sus quince autores proponen, pero no pocas veces sus ángulos de lectura se cruzan al recurrir a reconocidas autoridades sobre el tema, o al exponer de una u otra manera temáticas que relacionan lo sagrado con rupturas existenciales, experiencias extremas, realidades violentas; ángulos de análisis que hacen hincapié en la pérdida de sentido en términos de alejamiento de lo divino, falta, vacío, irrupción tremenda de lo otro, trituración del lenguaje; o inclusive dispositivos enunciativos desde donde leer lo sagrado en términos de gracia mística, pero también de desacralización, humor e ironía. Todo esto pone en evidencia el interés de los investigadores aquí reunidos por retirar lo sagrado de las definiciones esencialistas y de los confines semánticos, para poder así discernir más y mejor sus significaciones y las implicancias éticas de la enunciación en el funcionamento eficaz de la ficción narrativa o del universo poético. Temáticas, perspectivas, dispositivos enunciativos hacen que la sacralidad se posicione en términos literarios como mirada sobre el sentido de la $\mathrm{H} /$ historia, y en consecuencia, como modo de representación que lumínicamente nos recuerda lo que toda textualidad significa a pesar de lo que su apariencia nos dicta que es.

\section{BiBLIOGRAFÍA}

Benjamin, Walter. "La obra de arte en la época de su reproductibilidad técnica”. [1936]. Discursos interrumpidos I. Madrid: Taurus, 1982.

Berger, Peter L. A Rumor of Angels. Modern Society and the Rediscovery of the Supernatural. [1969]. New York: Open Road Integrated Media, 2011.

Blanchot, Maurice. L'espace littéraire. [1955]. Paris: Gallimard, 1988.

Caillois, Roger. L'homme et le sacrée. [1950]. Paris: Gallimard, 1988.

Deleuze, Gilles y Claire Parnet. Dialogues. Paris: Flammarion, 1996.

Eliade, Mircea. Le Sacrée et le profane. [1965]. Paris: Gallimard, 1987.

Miller, Jacques-Alain. "Le Retour du blasphème”. Lacan Quotidien 28 (2015). 10 enero 2015. WEB.

Foucault, Michel. "Le Souci de soi”. Histoire de la sexualité. Paris: Gallimard, 1984.

Otto, Rudolf. Lo santo, lo racional y lo irracional en la idea de Dios. [1917]. Madrid: Revista de Occidente, 1965.

Rancière, Jacques. Politique de la littérature. Paris: Editions Galilée, 2007.

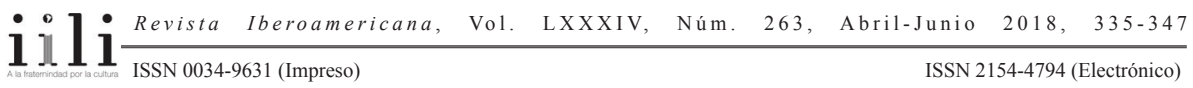


